assembly and disassembly and the tubulininteractions will appear to be hiometric. Since no assumptions were concerning specificity, it is evident while constancy of composition is istent with specificity of interaction, not a sufficient condition and the stion on whether any of the MAPs (be HMW or tau) are specific or not must regarded as still open. A similar conusion has been reached recently by villiams, Jr. [26] who examined by gant two-dimensional electrophoresis periments the question of which MAPs qualify as potential candidates for ecific liganding to tubulin.

The nature of the participation of the MAPs in the microtubule system has been questioned also by observations that a variety of polycationic macromolecules, uch as histones, ribonuclease, DEAE dextran and poly-L-lysine, can mimic their effect in microtubule reconstitution, [27] to he extent of affecting $\mathrm{C}_{\mathbf{r}}$ in similar manner o MAPs [28]. On the other hand, a number of reports have presented circumstantial evidence favoring the proposition that the MAPs are microtubule-related. First, electron micrographs of microtubules reconstituted in the presence of these proteins display decorations similar to those observed on natural microtubules $[22,23]$. Secondly, immunofluorescence experiments have been interpreted as indicating that some of the MAPs are located in cells in networks similar to those formed y microtubules $[29,30]$. Yet, none of these observations can be regarded as more than preliminary and suggestive, so that, at present, it seems most prudent to regard as unresolved the question of the participation in microtubule assembly in vivo, as well as in vitro, of the non-tubulin proteins (MAPs), such as HMW or tau.

\section{Summary}

The present day status of in vitro nicrotubule assembly may be summarized follows. The minimal requirements are: pure tubulin, GTP, probably $\mathrm{Mg}^{2+}$ and the bsence of $\mathrm{Ca}^{2+}$. Thermodynamically, ssembly fits the model of a nucleated coperative polymerization. The growth step is entropy driven and involves the release water molecules. The reaction requires GTP, which is probably hydrolyzed during sembly. The process can be enhanced by -specific thermodynamic boosters, as concentrated glycerol, and by a iety of polycations which stabilize the embled structure by binding to it. It is clear at present what macromolecular control microtubule assembly in vivo or which, if any, of the proteins frequently co-crystallized with tubulin during its isolation have any specific relation to the microtubule system.

\section{Acknowledgment}

This research was generously supported by Grants from the U.S. Public Health Service (GM-14603 and CA 16707).

\section{References}

1 Lee, J. C., Frigon, R. P. and Timasheff, S. N. (1973) J. Biol. Chem. 248, 7253-7262

2 Frigon, R. P. and Timasheff, S. N. (1975) Biochemistry 14, 4559-4566

3 Weisenberg, R. C., Borisy, G. G. and Taylor, E. W. (1968) Biochemistry 7, 4466-4479

4 Weisenberg, R. C. (1972) Science 177, 1104 1105

5 Borisy, G. G. and Olmsted, J. B. (1972) Science 177, 1196-1197

6 Weisenberg, R. C. and Timasheff, S. N. (1970) Biochemistry 9, 4110-4116

7 Shelanski, M. L., Gaskin, F. and Cantor, C. (1973) Proc. Nat. Acad. Sci. U.S.A. 70, 765768

8 Gaskin, F., Cantor, C. R. and Shelanski, M. L. (1974) J. Mol. Biol. 89, 737-756

9 Oosawa, F. and Kasai, M. (1971) in Biological Macromolecules Timasheff, S. N. and Fasman, G. D. eds), Volume 5, pp. 261-322, Dekker, N. Y.

10 Kirschner, M. W., Williams, R. C., Weingarten, M. and Gerhart, J. C. (1974) Proc. Nat. Acad. Sci. U.S.A. 71, 1158-1163

11 Erickson, H. P. (1974) J. Supramol. Struct. 2, 393-411

12 Lee, J. C. and Timasheff, S. N. (1975) Biochemistry 14, 5183-5187
13 Lee, J. C. and Timasheff, S. N. (1977) Biochemistry 16, 1754-1764

14 Wyman, J. (1964) Adv. Protein Chem. 19, 224-285

15 Timasheff, S. N., Gorbunoff, M. J. and Hinz, H.-J. (1978) Fed. Proc. 37, 1790

16 Salmon, E. D. (1975) Science $189,884-886$

$17 \mathrm{Na}, \mathrm{C}$. and Timasheff, S. N. (1978) Fed. Proc. 37,1791

18 Weisenberg, R. C., Deery, W. J. and Dickinson, P. J. (1976) Biochemistry 15, 4248-4254

19 David-Pfeuty, T., Erickson, H. P. and Pantaloni, D. (1977) Proc. Nat. Acad. Sci. U.S.A. 74,5372

20 Penningroth, S. M. and Kirschner, M. W. (1977) J. Mol. Bio . 115, 643-673

21 Olmsted, J. B. and Borisy, G. G. (1975) Biochemistry 14, 2996-3005

22 Murphy, D. B. and Borisy, G. G. (1975) Proc. Nat. Acad. Sci. U.S.A. 72, 2696-2700

23 Sloboda, R. D., Dentler, W. L. and Rosenbaum, J. L. (1976) Biochemistry 15, 44974505

24 Cleveland, D. W., How, S.-Y. and Kirschner, M. W. (1977) J. Mol. Biol. 116, 207-225

25 Borisy, G. G., Marcum, J. M., Olmsted, J. B., Murphy, D. B. and Johnson, K. A. (1975) Ann. N.Y. Acad. Sci. 253, 107-132

26 Berkowitz, S. A., Katagiri, J., Binder, H. K. and Williams, Jr., R. C. (1977) Biochemistry $16,5610-5617$

27 Erickson, H. P. and Voter, W. A. (1976) Proc. Nat. Acad. Sci. U.S.A. 73, 2813-2817

28 Lee, J. C., Tweedy, N. and Timasheff, S. N. (1978) Biochemistry, 17, 2783-2790

29 Sherline, P. and Schiavone, K. (1977) Science $198,1038-1040$

30 Connolly, J. A., Kalnins, V. I., Cleveland, D. W. and Kirschner, M. W. (1977) Proc. Nat. Acad. Sci. U.S.A. 74, 2437-2440

\title{
The biosynthetic pathway of the asparagine-linked oligosaccharides of glycoproteins
}

\author{
R. J. Staneloni and L. F. Leloir
}

A dolichyl diphosphate oligosaccharide containing glucose, mannose and $\mathrm{N}$-acetylglucosamine is the precursor of the sugar moiety of some glycoproteins. Studies of glycoproteins produced by virus-infected cells, using endo- $\mathrm{N}$-acetylglycosaminidase for the liberation of the sugar moiety, have shown that the glucose-containing oligosaccharide is transferred to protein, then the glucose and some mannose residues are removed and acetlyglucosamine, galactose and sialic acid are added.

Sugar addition to protein leading to the formation of glycoproteins occurs either directly from the sugar nucleotides or indirectly through lipid intermediates. The latter pathway was reviewed in TIBS [1] (see also [2,3]).

Recent work has shown that the asparagine-linked oligosaccharides are first built

R. J. Staneloni and L. F. Leloir are at the Instituto de Investigaciones Bioquimicas 'Fundación Campomar' and Facultad de Ciencias Exactas y Naturales, Obligado 2490, Buenos Aires (28), Argentina. up on a lipid, then transferred to polypeptide and modified by removal or addition of monosaccharide residues. This work has been based mainly on the finding of a glucose-containing lipid-oligosaccharide, on the discovery of enzymes, the endo- $N$ acetylglucosaminidases, which release some oligosaccharides from glycoproteins and on the use of virus-infected cells.

\section{Asparagine-linked oligosaccharides}

The structures of the oligosaccharides, the biosynthesis of which is considered in 
two $\mathrm{N}$-acetylglucosamine residues of the

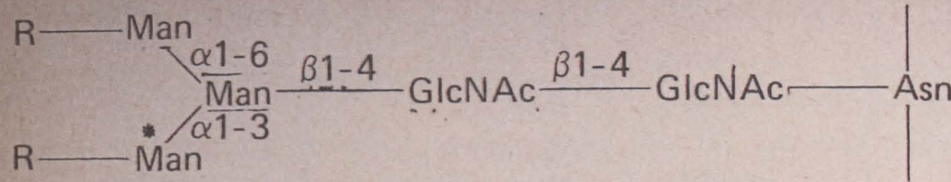

High-mannose type: $R=(\alpha \operatorname{Man})_{n}$

Complex type: $R=$ Sial; $2-3$ Gai; $\beta 1-4$ CIcNAc $\beta 1-2$

Fig. 1. Structures of the asparagine-linked oligosaccharides. The residues within the dotted circles may be absent. See the text for the explanation of the asterisk (*).

this review, are shown in Fig. 1. Two types of oligosaccharides have been found: the high-mannose and the complex type. Both have a common pentasaccharide structure and differ in the R-side chains. In the highmannose type the side chains have a variable number of mannose residues and different types of ramification. In some cases, as in the ovalbumin oligosaccharides, there may be, in addition, some acetylglucosamine residues in the side chains. In the complex type the side chains have galactose, $\mathrm{N}$-acetylglucosamine and sialic acid, but some may be incomplete. In some cases, as in the $\alpha$ acid-glycoprotein of serum and in the vesicular stomatitis virus glycoproteins, there are three R-chains instead of the two shown in Fig. 1. Thus there is a considerable variety of oligosaccharides but with a common pentasaccharide core.

\section{The G-oligosaccharide}

About 10 years ago it was found that a liver enzyme would form dolichyl diphosphate glucose (Fig. 2) by transfer of glucose from UDPglucose to dolichyl phosphate [4]. The compound was then found to react with an endogenous acceptor to yield a substance insoluble in most organic solvents but soluble in chloroform-methanolwater $(1: 1: 0.3)$ [5]. Mild acid treatment led to the liberation of a substance which appeared to be dolichyl phosphate and of another compound which had the properties of an oligosaccharide [6]. Treatment of the methyl glycoside of the latter with alkali led to the appearance of two positive charges that were interpreted to arise by deacetylation of two hexosamine residues [7]: On paper chromatography with butanol-pyridine-water $(4: 3: 4)$ or with nitromethane- $n$-propanol-water $(2: 5: 3)$ it was found to migrate with the $R_{\mathrm{F}}$ value of malto-oligosaccharides of $15-16$ or $11-12$ units respectively [8]. The original work has been perfected [9-11], and now the oligosaccharide is considered to have the composition: mannose $_{9} \mathrm{~N}$-acetylglucosamine $_{2}$ glucose $_{2}$ [12]. Its structure is presumably similar to a high mannose type of oligosaccharide, with the additional glucose residues. The glucose-containing oligosaccharide combined to dolichyl diphosphate was called glucosylated endogeneous acceptor in the initial studies and more recently has been referred to as Goligosaccharide [8].

There is evidence that the biosynthetic pathway of dolichyldiphosphate G-oligosaccharide is as shown in Fig. 3. The different steps in which $\mathrm{N}$-acetylglucosamine, mannose and glucose are added to dolichyl phosphate have been studied separately with microsomal enzymes of various types of cells [1-3]. The reaction which follows, that is the transfer of the Goligosaccharide to protein, also seems to be of universal occurrence, at least in animal tissues. However, for some time dolichyl diphosphate G-oligosaccharide was considered to be an oddity because no glycoprotein carrying such a saccharide had been described.

\section{Endo $N$-acetylglucosaminidase}

The development of a procedure for removing the amino acid or polypeptide has been a difficulty in the study of asparagine-linked oligosaccharides. Removal of the oligosaccharide is obtained by heating the glycoprotein for about $6 \mathrm{~h}$ in $2 \mathrm{~N}$ hydroxide plus sodium borohydride [13]. Another procedure is to use an endo $\mathrm{N}$-acetylglucosaminidase. These enzymes act by hydrolysing the bond between the

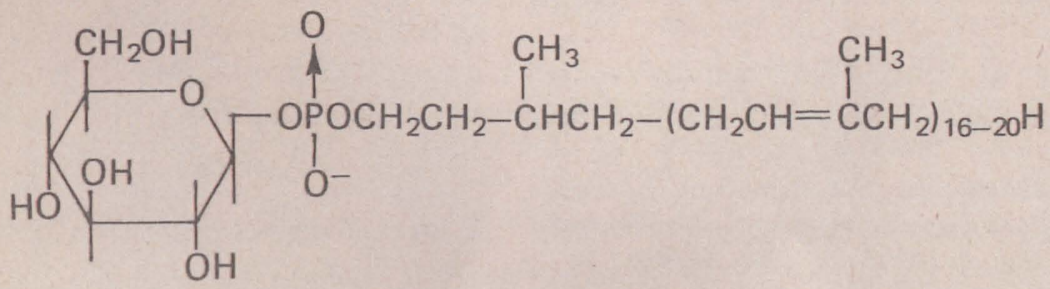

Fig. 2. Dolichyl phosphate glucose. core (Fig. 1). One of the enzymes was detected by Tarentino and Maley [14] in Streptomyces griseus extracts. This enzyme was called $\mathrm{H}$ because it acts on the highmannose type of oligosaccharides containing five or more mannoses but not on the complex type. The di- $N, N^{\prime}$-acetylchitobiose residue is split, irrespective of whether the first $N$-acetylglucosamine is free, reduced or joined to lipid, to asparagine or to an asparagine residue in a protein [15].

Another endo $\mathrm{N}$-acetylglucosaminidase (endo D) was detected in Diplococcus pneumoniae [16]. It only acts on oligosaccharides which have no substituent on the mannose residue marked with an asterisk $\left({ }^{*}\right)$ in Fig. 1.

Other enzymes were found in Clostridium perfringens. They were referred to as $\mathrm{C}_{\mathrm{I}}$ and $\mathrm{C}_{\mathrm{II}}$ and had specificities similar to endo $\mathrm{D}$ and $\mathrm{H}$ respectively [17].

\section{Studies with virus-infected cells}

Animals cells infected with certain viruses are an excellent material for the study of glycoprotein synthesis. Sindbis and vesicular stomatitis virus (VSV) are o the RNA type and have a coat containing glycoproteins. The oligosaccharide of the VSV glycoprotein is of the complex type and in Sindbis there are two glycoproteins each having a high-mannose and a complex oligosaccharide. On infection the protein synthesis of the host cell is suppressed and replaced by that of virus protein. The biosynthesis of the oligosaccharide moiety is carried out by the host cells' glycosy transferases $[18,19]$. However, differen viruses acting in the same cells may lead to the formation of different oligosaccharides [20]. This is an indication that the poly. peptides contain information which determines at which point a high-mannose or a complex oligosaccharide is to be added to it.

Studies with virus-infected cells hav been carried out by three groups of worker and most interesting results have bee obtained. Robbins et al. [21] gave pulses 0 $\left[{ }^{3} \mathrm{H}\right]$ mannose (or $\left.{ }^{35} \mathrm{~S}\right]$ methionine) to en bryonic chick cells infected with VSV an examined the proteins by polyacrylamid gel electrophoresis, with or without pre vious treatment with endo $H$. All of t protein-linked oligosaccharide formed itially was released by endo $\mathrm{H}$ but during chase period the glycoprotein becan increasingly resistant to the enzyme. Th is as if the oligosaccharide formed initial was the high-mannose type and pr gressively became the complex type. 
